\title{
Differences in the Anthocyanin Profile of Different Tissues of the Strawberry Fruit ${ }^{+}$
}

\author{
Hung T. Hong ${ }^{1, *}$, Aiqi Chen ${ }^{2}$, Michael E. Netzel ${ }^{1}$ and Tim J. O'Hare ${ }^{1}$ \\ 1 Centre for Nutrition and Food Sciences, Queensland Alliance for Agriculture and Food Innovation, \\ The University of Queensland, Coopers Plains, Brisbane, QLD 4108, Australia; \\ m.netzel@uq.edu.au (M.E.N.); t.ohare@uq.edu.au (T.O.H.) \\ 2 School of Agriculture and Food Sciences, The University of Queensland, St. Lucia, Brisbane, QLD 4067, \\ Australia; aiqi.chen@uq.net.au \\ * Correspondence: h.trieu@uq.edu.au; Tel.: +61452233955 \\ + Presented at the third International Tropical Agriculture Conference (TROPAG 2019), Brisbane, Australia, \\ 11-13 November 2019.
}

Published: 20 January 2020

\begin{abstract}
Strawberries are most commonly red in colour, which is largely due to the anthocyanin, pelargonidin-3-glucoside, a bioactive flavonoid with potential health benefits. Variation in the intensity of red colour across strawberry varieties, from a light pink to a deep cherry colour, is solely associated with a change in concentration of this single anthocyanin, rather than the synthesis of an anthocyanin with a different colour. In this study, the anthocyanin profiles of the two constituent edible tissues of strawberry fruit were determined. The main tissue of the strawberry consists of a swollen fleshy receptacle. The second tissue consists of the achenes, visible on the surface of the strawberry, with each achene consisting of a dry single-seeded fruit formed from a fertilised ovule. The current study showed that the anthocyanin profile of a strawberry achene is totally different from that of the receptacle. While red-coloured pelargonidin-3-glucoside is the main anthocyanin component (about 94\%) in the receptacle, purple-coloured cyanidin-3-glucoside accounts for approximately $90 \%$ of the anthocyanin content in the achene. This would indicate that flavonoid 3'hydroxylase $\left(\mathrm{F}^{\prime} \mathrm{H}\right)$, the enzyme responsible for shifting anthocyanin biosynthesis towards cyanidin and away from pelargonidin, is functional in strawberry achene tissue, but not in the receptacle tissue. This may indicate that other factors, such as transcription factors, can modulate the anthocyanin profile of different strawberry tissues, rather than strawberries having a non-functional F3' $\mathrm{H}$ gene. However, the relevance of these findings for potential strawberry breeding programs and subsequently the nutritional quality of strawberry fruit needs to be investigated further.
\end{abstract}

Keywords: strawberry; anthocyanin profile; tissues

Funding: This study was funded in part by 'Naturally Nutritious' (Horticulture Innovation Ltd., project HN 15001).

Acknowledgments: Special thanks are extended to Strawberry Production Systems, Horticulture and Forestry Science, Department of Agriculture and Fisheries, QLD, Australia.

Conflicts of Interest: The author declares no conflict of interest.

(C) 2020 by the authors. Licensee MDPI, Basel, Switzerland. This article is an open access article distributed under the terms and conditions of the Creative Commons Attribution (CC BY) license (http://creativecommons.org/licenses/by/4.0/). 